\title{
Os Conselhos Municipais de Saúde: uma revisão da literatura sobre seus limites e potencialidades
}

\author{
Kênia Mara Gaedtke* \\ Márcia Grisotti**
}

\begin{abstract}
Resumo
O ineditismo e as proporções dos conselhos de saúde como ação de publicização do Estado fomentaram uma produção acadêmica bastante considerável sobre o tema. Grande parte destas produções apresenta o fato de que a institucionalização dos conselhos de saúde não garante necessariamente o efetivo controle social, participação e democratização nas/das políticas de saúde. Este trabalho procura rever parte desta literatura, mapeando os limites apontados e apresentandoos através das relações estabelecidas no e a partir do conselho municipal de saúde. Espera-se demonstrar que as dificuldades encontradas pelos conselhos para sua efetividade e legitimidade resultam de diversos fatores interdependentes, que, se analisados isoladamente, podem levar a conclusões simplistas.
\end{abstract}

Palavras-chave: Sistema Único de Saúde, Conselhos de Saúde, participação, controle social.

\section{Introdução}

A s políticas públicas em geral, e as políticas públicas de saúde, Aem particular, são um importante objeto para a compreensão

\footnotetext{
Mestre pelo Programa de Pós-Graduação em Sociologia Política da UFSC. Professora colaboradora na Universidade do Estado de Santa Catarina (UDESC), Florianópolis. Núcleo de Ecologia Humana e Saúde - Programa de Pós-Graduação em Sociologia Política da Universidade Federal de Santa Catarina. Endereço eletrônico: anasaccol@ccs.ufsc.br.

*** Professora do Departamento de Sociologia e Ciência Política da Universidade Federal de Santa Catarina, Florianópolis. Núcleo de Ecologia Humana e Saúde - Programa de Pós-Graduação em Sociologia Política - UFSC. Endereço eletrônico: grisotti@fastlane. com.br.
} 


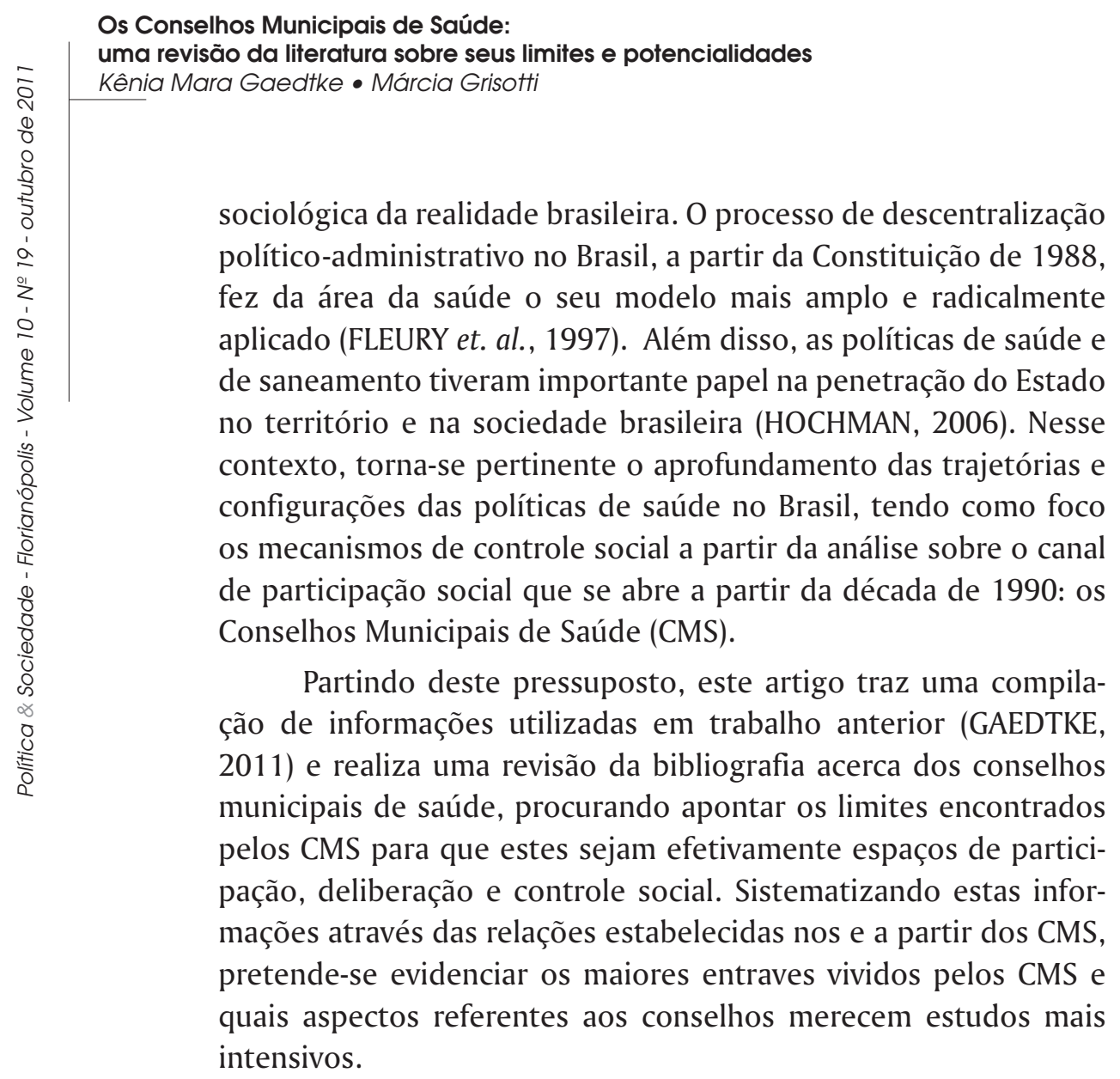

As políticas de saúde no Brasil: participação e controle social. Onde entram os Conselhos Municipais de Saúde?

A criação do Sistema Único de Saúde (SUS) foi resultado de um longo processo de lutas e negociações, sendo proposto e complementado na Lei Orgânica de 1990 e nas Normas Operacionais Básicas de 1993 e 1996. Com base nos preceitos da Constituição de 1988, este modelo de assistência em saúde prevê a operacionalização dos seguintes princípios:

a) Universalidade e equidade - Acesso aos serviços de saúde garantido à toda a população, sem distinção, e levando em consideração as necessidades específicas de cada grupo e/ou indivíduo. 
b) Descentralização - As ações e os serviços de saúde passam a ser gestadas pelos estados, municípios, distritos e unidades locais de saúde, através da transferência de recursos e de poder de decisão.

c) Integralidade - as ações de saúde devem estar voltadas para a promoção, prevenção e recuperação da saúde, levando em conta que o usuário do sistema é um ser social integrante de uma realidade concreta. Este princípio prevê romper com ofertas descoordenadas dos serviços de saúde.

d) Regionalização, hierarquização e resolutividade - em busca da máxima suficiência e eficácia nos atendimentos municipais e regionais, com unidades de saúde articulando-se conforme níveis de atenção, garantindo a referência e contra-referência dos usuários.

e) Participação - Este princípio prevê que o SUS deve ser administrado com a participação direta dos usuários e trabalhadores da saúde, através principalmente das Conferências e dos Conselhos de Saúde. (BRASIL, 1992)

Mais de vinte anos após a criação do Sistema Único de Saúde, o que se percebe é que cada um destes princípios ainda apresenta uma série de dificuldades na busca por consolidação. Mesmo que se tenha a consciência de todos estão intrinsecamente ligados, neste trabalho propõem-se atenção especial a um destes princípios norteadores, que trata da participação e controle social. Para isso, é importante retomar a forma como o próprio conceito de "controle social" foi se invertendo. De acordo com Correia (2005), nas ciências política e econômica a expressão controle social é ambígua, construída no eixo da relação entre Estado e Sociedade Civil, e apresenta duas concepções diferentes. A primeira concepção entende controle social como controle do Estado sobre a sociedade. Neste sentido, segundo o Dicionário de Política, controle social é:

o conjunto de meios de intervenção, quer positivos quer negativos, acionados por cada sociedade ou grupo social a fim de induzir os próprios membros a se conformarem às normas que a caracteri- 


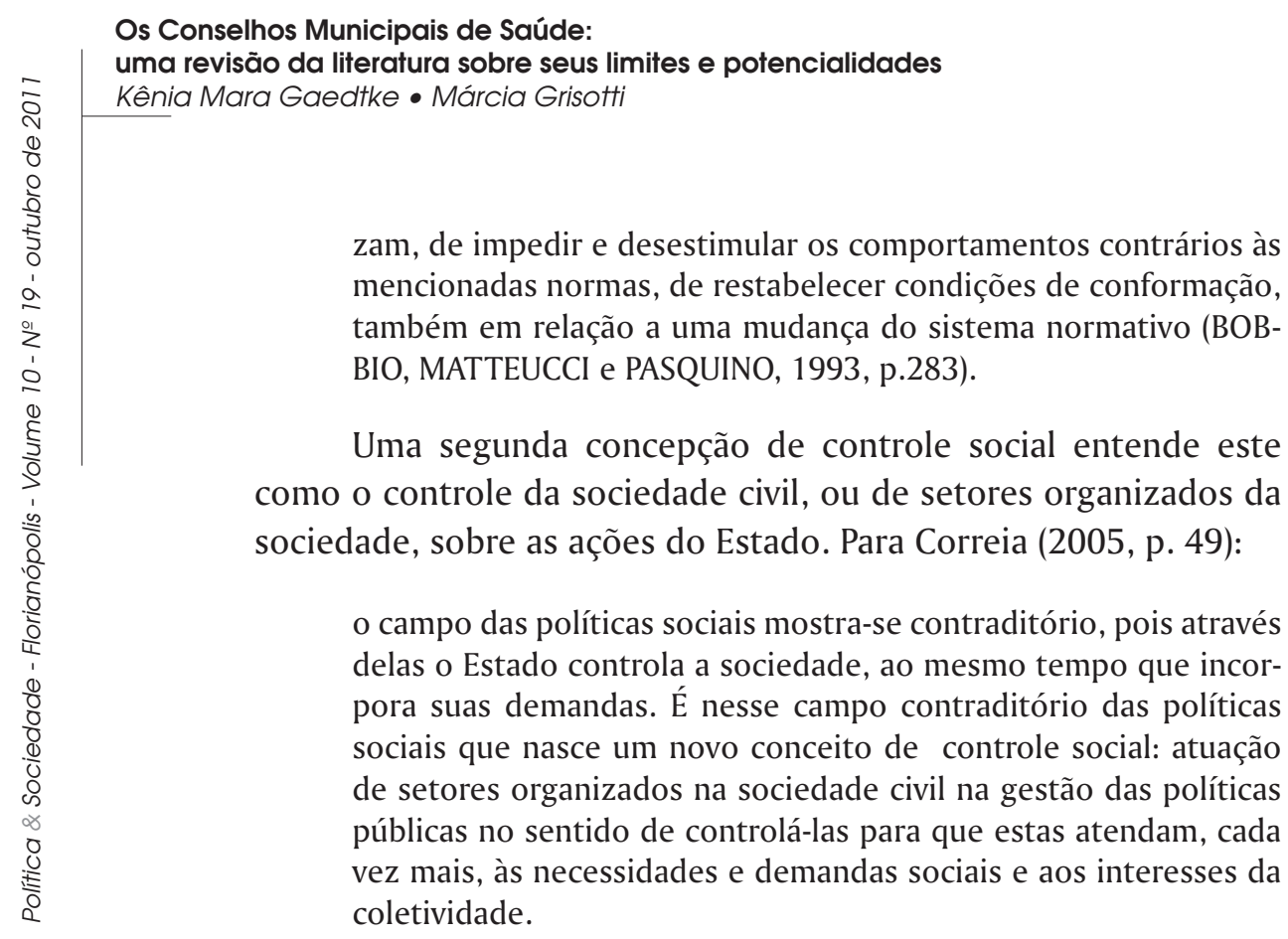

É nesta segunda concepção, fortalecida no contexto das políticas sociais, que a ideia de controle social passa a ser atribuída à participação da população. E o controle social em saúde, a partir da implantação do SUS, é previsto através dos conselhos e conferências, nas instâncias federal, estaduais e municipais.

\section{A produção acadêmica sobre os Conselhos Municipais de Saúde}

Quando se trata da produção acadêmica sobre os conselhos gestores municipais, percebe-se que já há uma literatura considerável sobre o tema. Côrtes (2004) divide essa literatura sobre conselhos em dois conjuntos de trabalhos: as pesquisas e avaliações que descrevem processos participativos em conselhos municipais particulares, e outros que elaboram panoramas gerais sobre os tipos de conselhos existentes. Para a autora, estes trabalhos

formam um acervo de dados empíricos que tem subsidiado o debate acadêmico e político sobre o tema. Eles possibilitam a formulação de generalizações sobre o funcionamento e papel desempenhado pelos conselhos no contexto de cada área de política 
pública e nas transformações gerais que o sistema de proteção brasileiro enfrentou. (CÔRTES, 2004, p. 251)

De acordo com o Ministério da Saúde (BRASIL, 1992), Conselho de Saúde é o órgão ou instância colegiada de caráter permanente e deliberativo, em cada esfera de governo, integrante da estrutura básica da Secretaria ou Departamento de Saúde dos Estados e Municípios, com composição, organização e competência fixadas em lei. Os Conselhos de Saúde Estaduais e Municipais podem, conforme o Ministério da Saúde:

1. Atuar na formulação e controle de execução da política de saúde, incluídos seus aspectos econômicos, financeiros e de gerência técnico-administrativa;

2. Estabelecer estratégias e mecanismos de coordenação e gestão do SUS, articulando-se com os demais colegiados em nível estadual e municipal;

3. Traçar diretrizes às diversas realidades epidemiológicas e a capacidade organizacional dos serviços;

4. Propor a adoção de critérios que definam qualidade e melhor resolutividade, verificando o processo de incorporação dos avanços científicos e tecnológicos na área;

5. Propor medidas para o aperfeiçoamento da organização e do funcionamento do Sistema Único de Saúde;

6. Examinar propostas e denúncias, responder a consultas sobre assuntos pertinentes a ações e serviços de saúde, bem como apreciar recursos a respeito das deliberações do Colegiado;

7. Fiscalizar e acompanhar o desenvolvimento das ações e serviços de saúde;

8. Propor a convocação e estruturar a comissão organizadora das Conferências Estaduais e Municipais de Saúde; 


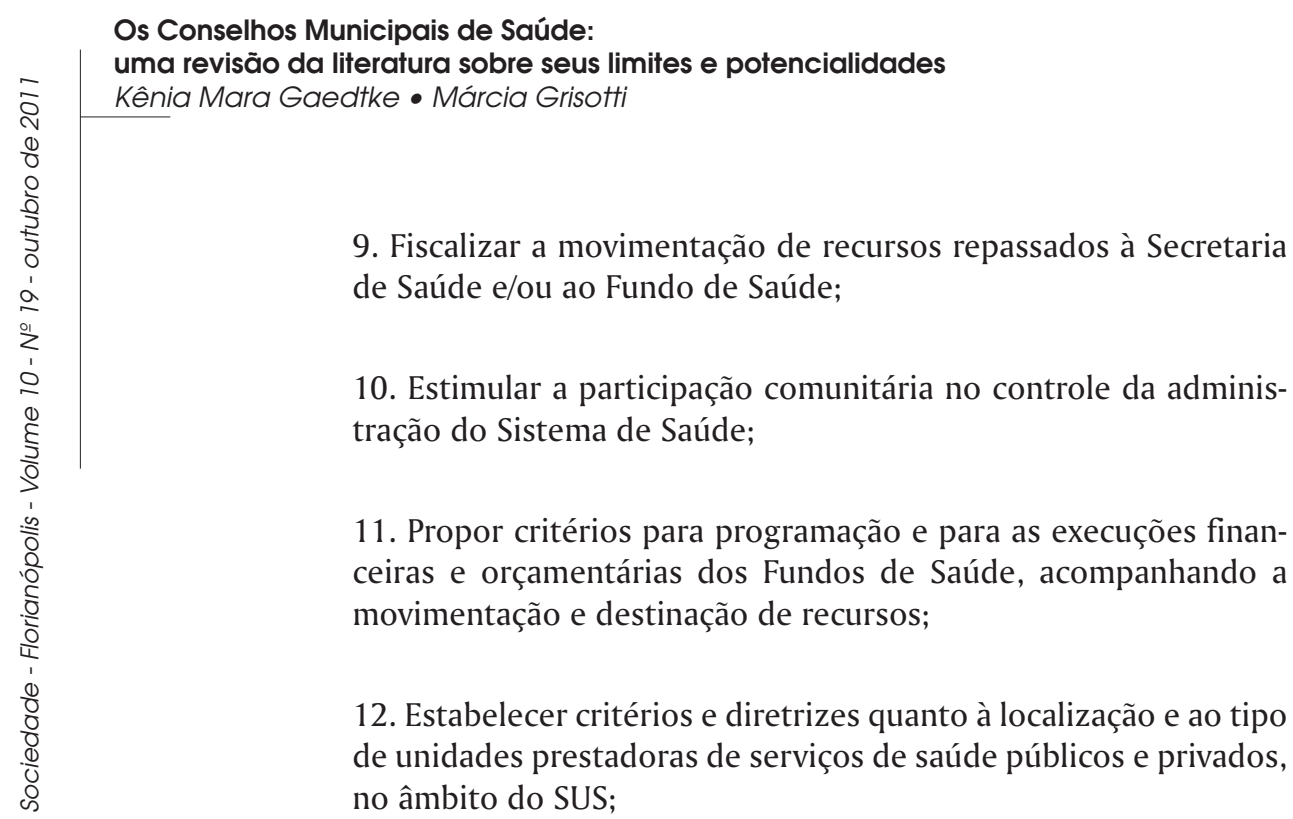
no âmbito do SUS;

13. Elaborar o Regimento Interno do Conselho e suas normas de funcionamento;

14. Estimular, apoiar ou promover estudos e pesquisas sobre assuntos e temas na área de saúde de interesse para o desenvolvimento do Sistema Único de Saúde;

15. Definir outras atribuições estabelecidas pela Lei orgânica da Saúde e pela IX Conferência Nacional de Saúde. (BRASIL, 1992)

Desta forma o Conselho necessita atuar tanto na formulação quanto no controle social sobre a execução da política de saúde, e tendo como pressupostos: a) a paridade do número de representantes dos usuários em relação do total de número de representantes dos segmentos do governo, dos prestadores de serviço e dos profissionais de saúde; e b) os representantes devem ter plenas condições para serem os legítimos defensores dos segmentos que representam (Ministério da Saúde, op. cit.).

O que se percebe na literatura revista é que, mesmo com muitos avanços, ainda há vários limites impostos para que haja um efetivo êxito destes conselhos. As fragilidades apontadas pelos diversos autores foram categorizadas e organizadas na forma do fluxograma a seguir (embora se tenha a consciência das dificul- 
dades de categorizar questões que se apresentam tão próximas e fluidas), que procura demonstrar as diferentes relações que se estabelecem a partir de um Conselho Municipal de Saúde, podendo servir de base para a construção de um panorama sobre os Conselhos no Brasil.

\section{Figura 1 - Fluxograma Conselhos Municipais de Saúde}

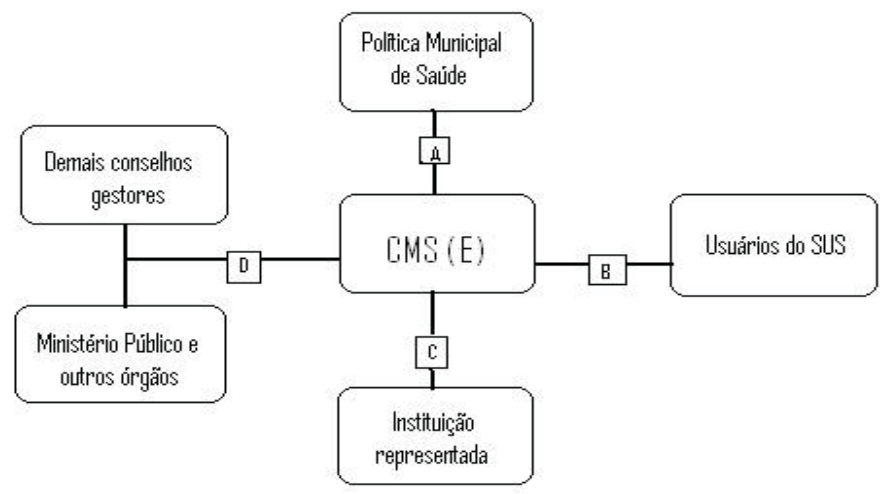

Fonte: Autores

Este fluxograma é uma tentativa de apresentar visualmente a complexidade que envolve uma análise dos conselhos municipais de saúde. Propor uma avaliação de êxito, participação e/ou efetividade de um CMS levando em conta apenas uma ou duas dessas relações pode ser um exercício demasiado simplista. Isso não significa que uma pesquisa não possa ou não deva priorizar uma análise centrada em algum aspecto específico, como sugere Heinich (2001, p. 123),

examinar o todo de um campo social não quer dizer exatamente examinar todos os seus acontecimentos. Trata-se de descobrir primeiramente as estruturas fundamentais que imprimem a todos os acontecimentos de um dado campo social, uma orientação e uma morfologia específicas. 


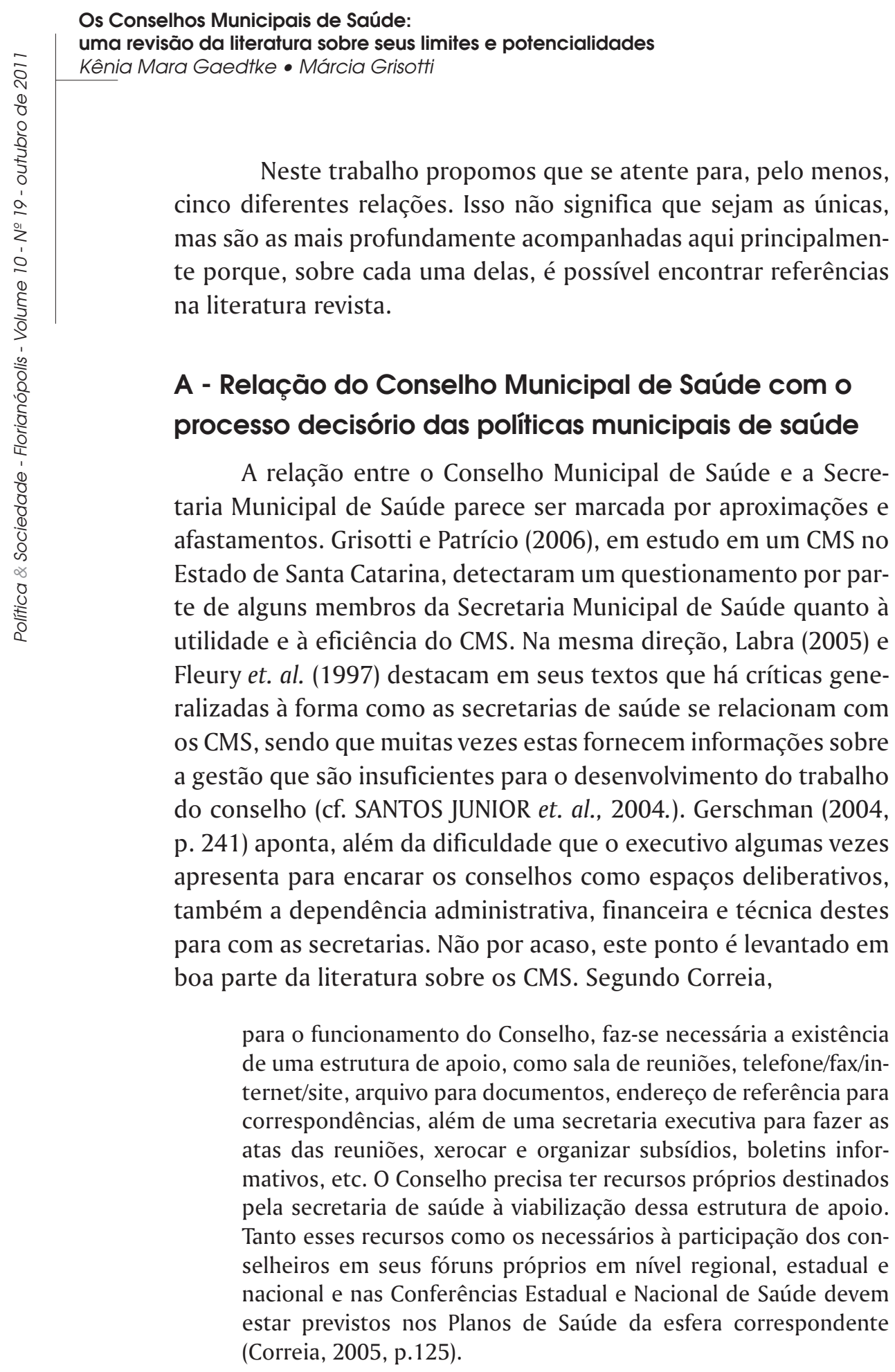


Moreira e Escorel (2009) também apontam essa questão como uma dificuldade. Estes autores, ao pesquisar 98\% dos CMS brasileiros, perceberam que a dimensão "autonomia" é a que apresenta os piores resultados. Para eles,

os CMS tendem a se tornar dependentes dos interesses políticos que dirigem o poder Executivo, ficando impedidos de, por exemplo, contratarem auditorias, pesquisas e consultorias que thes agreguem capacidade e saber técnico; de consolidarem agendas com outros conselhos e instituições; e de estabelecerem relação diária com a população (MOREIRA e ESCOREL, 2009, p.804).

Para estes autores, uma das maiores dificuldades para a consolidação da democratização via CMS está na visão dos gestores ultrapresidencialistas, que tendem a compreender o avanço da inclusividade como ameaça ao seu poder. Assim, seria fundamental a existência de um binômio "prefeitura participativa e sociedade organizada" para esta consolidação.

Menicucci (2005), partindo de uma perspectiva neo-institucionalista, aponta a dificuldade de se inverter uma relação historicamente dada sem que as consequiências das políticas anteriores não se façam perceber. Para a autora o processo de democratização:

permitiu a constituição e influência no processo decisório de novos atores, portadores de propostas alternativas para a saúde, em uma situação de desequilíbrios institucionais favoráveis à inovação institucional, mas que, pelo legado anterior, tendeu a inovações limitadas (MENICUCCI, 2005, p.51-52).

Além disso, é importante atentar que a secretaria e o conselho não são os únicos atores no palco de decisões sobre a política municipal de saúde, pois há também instituições privadas de prestação de serviços, que coexistem fortemente com o SUS num histórico enlace (TEIXEIRA e OLIVEIRA, 1986; MENICUCCI, 2005) e que constituem legalmente o Sistema através da Saúde Suplementar.

1 Dentre as dimensões "acesso", "autonomia" e "organização", utilizadas na referida pesquisa. 


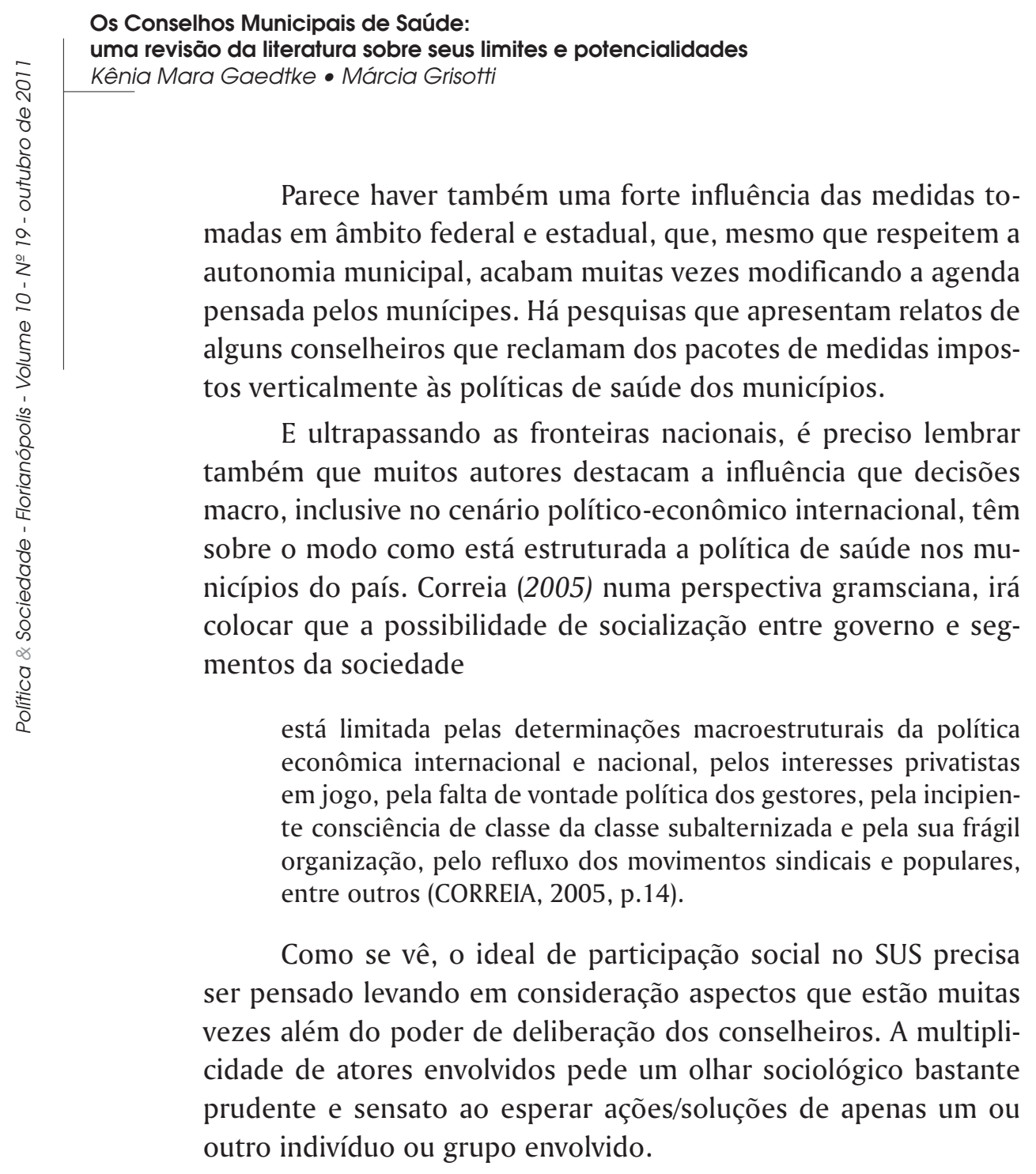

\section{B - Relação do Conselho Municipal de Saúde com a população usuária do SUS}

Aqui uma das questões que nos parece mais importante é a visibilidade dos conselhos. Segundo o Ministério da Saúde (2001, p. 83),

a visibilidade é uma condição que se caracteriza pela transparência da atuação dos conselhos. Neste sentido, devem ser criados canais de comunicação, por meio dos quais o Conselho presta contas 
do que faz à sociedade. A relação com os meios de comunicação local bem como a criação de boletins informativos e outros tipos de publicações, pelo próprio Conselho, são decisões importantes para garantir a visibilidade.

Correia (2005) coloca que há pouca visibilidade social das ações dos Conselhos. Gerschman (2004, p. 241) denuncia que algumas irregularidades que ocorrem levam a uma "completa inversão da ideia original dos conselhos", e faz uma forte crítica ao fato de que a maioria dos conselhos não opera como canalizador de demandas da população, não serve como espaço de denúncia e tampouco tem visibilidade (ou ações que visem ocupar espaços de comunicação) para as pessoas da localidade.

De fato, o número de cidadãos que sabem da existência ou, sabendo da existência, compreendem a função dos conselhos municipais de saúde parece ainda ser pequeno, sendo que um possível elemento de visibilidade para estes conselhos seria o fortalecimento dos conselhos locais, que se estabelecem mais próximos aos usuários, em suas comunidades. Grisotti e Patrício (2006, p.116) citam que alguns CMS, na tentativa de se aproximar dos usuários do SUS, realizam suas reuniões de forma itinerante, nas comunidades. No entanto, segundo as autoras, para o CMS, "o significado de aproximação com a comunidade diz respeito ao deslocamento físico até a comunidade, mantendo-se a pauta de discussões sem alterá-las em função das especificidades da comunidade e das pessoas que estão presentes", utilizando linguagem técnica e não contextualizando as discussões para as pessoas presentes.

Além disso, autores como Morita et. al. (2006, p. 54) criticam a forma como a burocracia impõe que da composição do conselho possam participar somente instituições formalmente organizadas, o que acaba por afastar grupos organizados e atuantes, mas que não têm estatuto legal e registro em cartório. Ainda mais crítica fica a situação de pessoas que não estão ligadas a qualquer tipo de organização ou associação, conforme destacado por Santos Junior et. al. (2004) e Coelho (2004). Ressalta-se assim que os autores analisados demonstram, quase que unanimemente, que ainda existe 


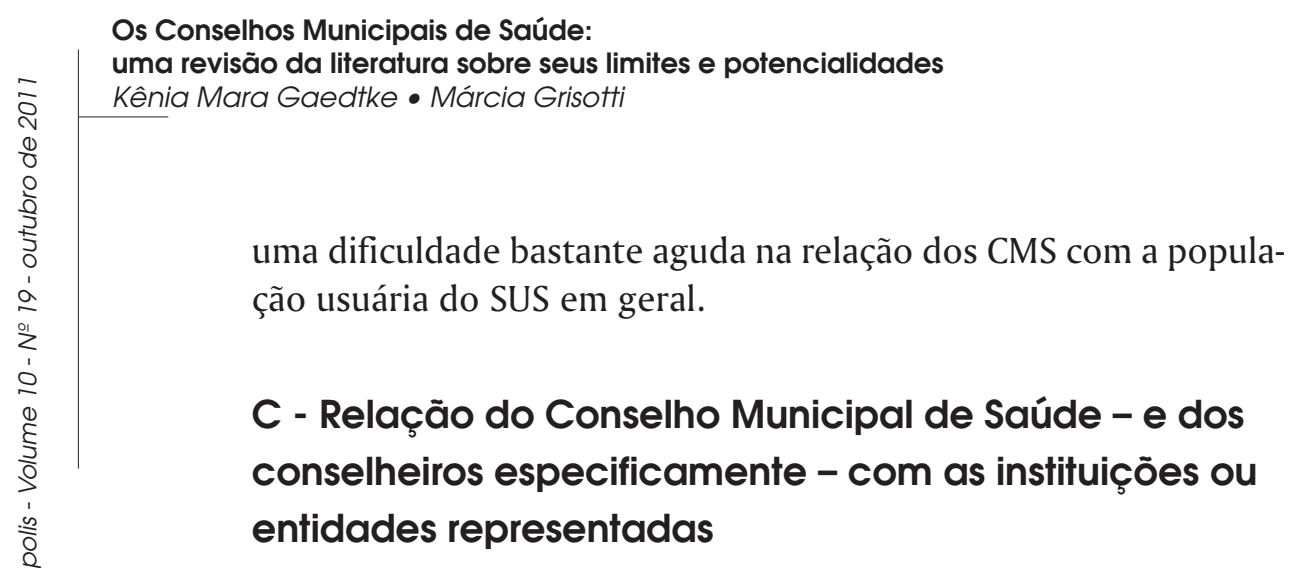

Uma das perguntas que se faz aqui é: "quem está sendo representado nos conselhos?" Há vários estudos que sugerem que o perfil dos representantes nos conselhos desenha uma espécie de elite participativa caracterizada por maior renda e escolaridade se comparada à média da população em geral. Lüchmann e Borba (2007), por exemplo, irão apresentar dados de municípios de Santa Catarina que corroboram com essa hipótese, assim como Santos Junior et. al. (2004) encontraram dados semelhantes em cinco regiões metropolitanas do país. Um apontamento a esse respeito é dado por Morita et. al. (2006, p. 54), que afirmam que as instituições costumam escolher o "melhor" ou "mais capacitado" como representante no conselho, o que, segundo estes autores, trazem questionamentos sobre a representatividade. Nesse sentido, discutem a ideia do representante como porta-voz, pois ainda há muita dificuldade em se realizar uma "representação representativa". Mesmo assim, as escolhas dos representantes podem estar vinculadas também a razões diferentes: tanto na literatura quanto na inserção ao campo empírico percebe-se que muitos conselheiros acabam sendo obrigados a representarem determinada instituição, sem vontade para tal, ou não confiando no poder de controle social do CMS. Estes aspectos fragilizam a representação, e distanciam o indivíduo conselheiro da base social da qual deveria ser reflexo. Segundo Correia (2005, p. 69), "o conselheiro deve estar bem informado e deve manter vínculo orgânico com a entidade que representa, levando suas posições e defendendo os interesses coletivos".

É possível perceber na literatura que os conselhos de saúde têm permitido a inserção dos usuários do sistema único de saú- 
de de uma maneira inclusive mais eficaz que em outros conselhos (como o de assistência social, por exemplo, conforme Côrtes, 2004). No entanto, como já citado acima, uma camada significativa da população acaba sem representação de nenhum tipo nesses espaços. Coelho (2004., p. 12) chama a atenção para o fato de que, não assegurando a todos os afetados pela política em questão a chance de terem seus interesses representados, é possível que haja "uma situação onde se reforçará a exclusão daqueles segmentos que não estiverem representados nos conselhos".

Em relação à participação dos movimentos sociais nos conselhos, pode-se citar Gerschman (2004, p. 246), que aponta que o Movimento Popular de Saúde, figura fundamental no processo de democratização das políticas da área, hoje se divide em opiniões divergentes quanto à participação ou não nos conselhos de saúde, o que segundo a autora abre espaço pra inserção de entidades profissionais (como as entidades médicas) defenderem prioritariamente interesses corporativos.

Com tudo isso, evidencia-se a perda dos espaços criados pela Reforma Sanitária para a efetivação da política de saúde, pois embora o movimento participe dos Conselhos, não os tem como próprios e decisórios para alcançar o sistema de saúde almejado pelas populações carentes (GERSCHMAN, 2004, p. 247).

Também Bógus (1998, p. 36) coloca que houve uma confusão em decorrência da criação dos conselhos, quando alguns movimentos sociais ligados à saúde não conseguiam distinguir os espaços, vendo os conselhos como seus prolongamentos. Para a autora, "a diferença, que deve ser mantida, entre os movimentos sociais e seu espaço de atuação e o espaço de participação popular institucionalizada, significa que o primeiro deve alimentar o segundo, mas não pode ser identificado ou se confundir com este".

Há outra questão vista como limite desta representação institucional: a frequente dificuldade de que ocorra uma comunicação 


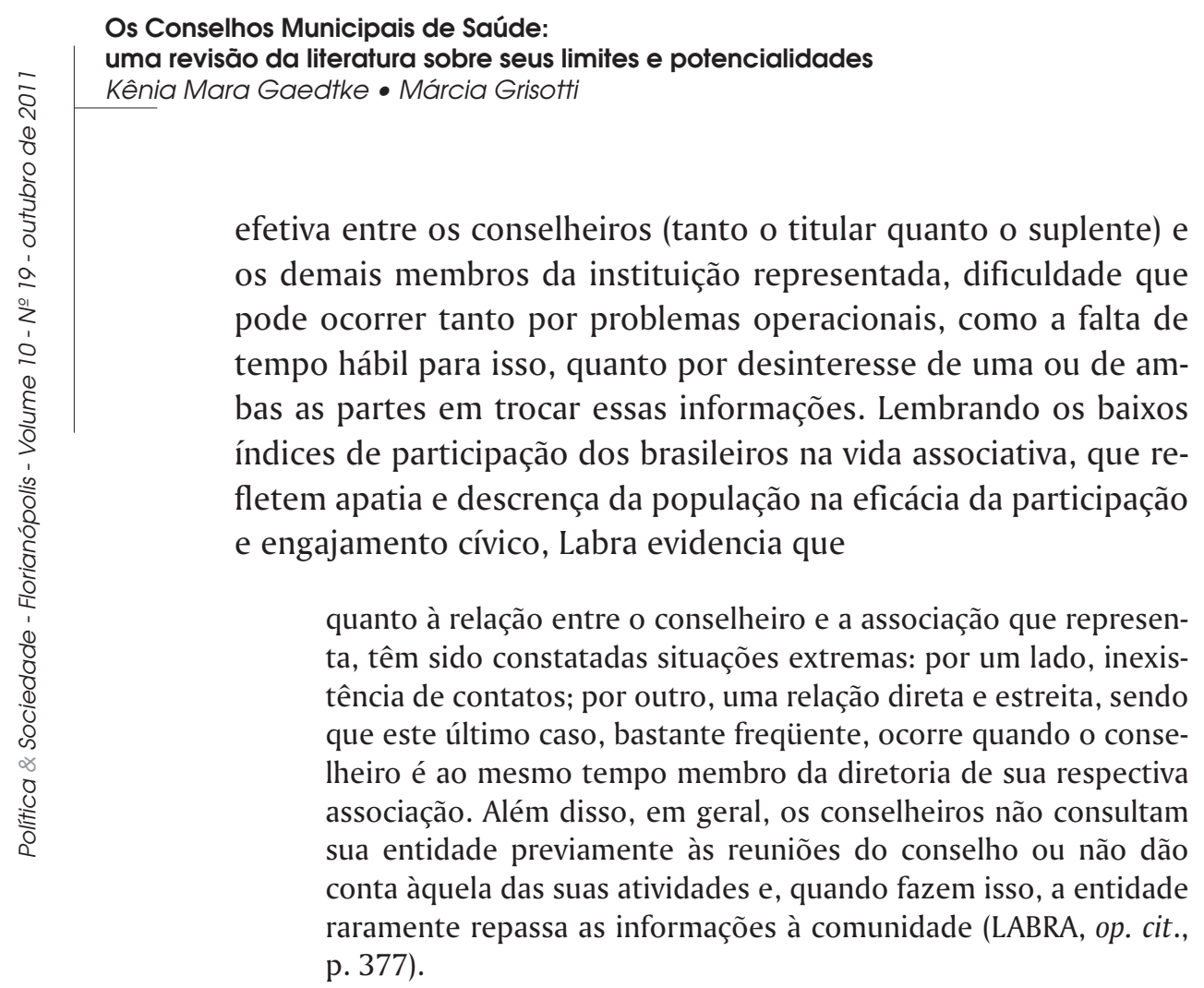

\section{D - Relação do Conselho Municipal de Saúde com os demais conselhos gestores, e destes com outros mecanismos de controle social (Ministério Público, Corregedoria e Promotoria)}

Este é um ponto que não recebe tanto destaque quanto outros na literatura referente aos conselhos municipais de saúde e tudo faz crer que estas relações deveriam ser objetos de um número maior de pesquisas, pois se entende que um conselho municipal de uma política específica, por mais atuante e fortalecido internamente e na sua relação com a secretaria, necessita estar inserido numa discussão ampliada sobre as políticas públicas não só da esfera municipal, mas também das demais. Acredita-se que isso the dá, além de maior visibilidade, também uma maior legitimidade e força no campo de disputa política.

Comerlatto et. al. (2007) defendem que é necessária uma intersetorialidade entre os conselhos gestores para que as políticas 
públicas deliberadas em um município sejam realmente orientadas a partir da demanda da sociedade. No entanto, colocam que esta intersetorialidade ainda é um desafio a ser perseguido. Para Santos Junior et. al. (2004) os conselhos municipais, em geral, ainda estão pouco aparelhados para o exercício da função de monitoramento de políticas públicas. Assim, uma das questões desta pesquisa é identificar se o diálogo estreitado entre conselhos do mesmo município fortaleceria essa capacidade de fiscalização e monitoramento.

Os autores acima sugerem que uma forma dessa intersetorialidade ocorrer é através da criação de estruturas no interior da administração,

do tipo "coordenadoria de conselhos municipais", responsáveis pela articulação e pela coordenação do funcionamento dos conselhos, com as atribuições de centralizar as informação referentes ao seu funcionamento e encaminhar suas resoluções e demandas para o poder público (SANTOS JUNIOR et. al., 2004, p. 42).

Já Correia (2005, p. 75) defende que é preciso "articular as deliberações dos conselhos, suas denúncias e lutas em torno do direito à saúde com o Ministério Público, Comissões de Saúde das Assembléias Legislativas e das Câmaras de Vereadores, e com a Promotoria dos Direitos do Consumidor (Procon)".

\section{E - As relações que se estabelecem no interior do Conselho Municipal de Saúde}

Este é um ponto bastante importante, que evidentemente está relacionado com todos os demais, afinal, atentar para as minúcias das relações estabelecidas no interior dos conselhos pode trazer elementos fundamentais à pesquisa. Aqui entram questões como, por exemplo, o convívio dos conselheiros nas reuniões, a participação e a deliberação no interior dos CMS, as comissões, a infra-estrutura, e a capacitação dos conselheiros.

Sobre a participação no interior dos conselhos, Wendhausen (2005, p.157), partindo de uma análise foucaultiana de poder, co- 


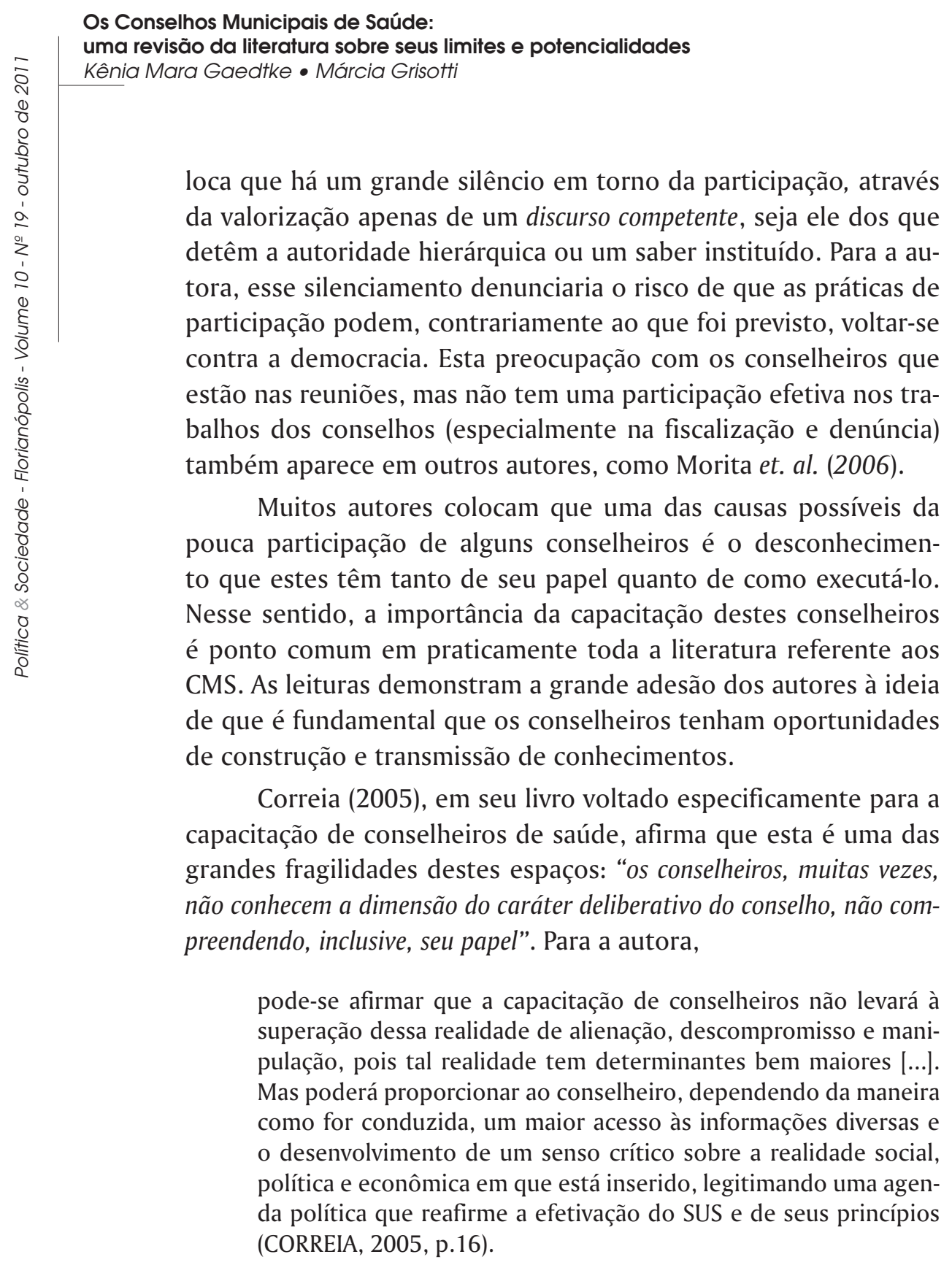

Wendhausen (2005, p. 158) coloca que "a formação de conselheiros através de pólos de educação permanente é uma das alternativas para socializar informações que são fundamentais para sua atuação."

O Conselho Nacional de Saúde (CNS) formulou, a fim de 
atender a uma demanda de todas as regiões do país, diretrizes nacionais para a capacitação de conselheiros de saúde. Neste documento (BRASIL, 2003), o CNS afirma que

é fundamental desencadear processos de capacitação de Conselheiros de Saúde que possibilitem, além da compreensão da estrutura e funcionamento do SUS e do processo de construção do modelo assistencial adequado a princípios e diretrizes, também uma compreensão ampliada de saúde, na qual seja possível uma maior articulação intersetorial, de modo que a ação do Conselho possa ser caracterizada como de formulação e deliberação de políticas públicas comprometidas com a qualidade de vida (BRASIL, 2003, p. 7).

As diretrizes colocam a necessidade de uma capacitação descentralizada, contínua e permanente, levando em consideração as particularidades de cada estado e município. A preocupação com que estes momentos não sejam meros "eventos", com transmissão verticalizada de conhecimentos, do técnico para o leigo, remete à leitura de Oliveira (2004), que trata da informação e da comunicação no interior dos conselhos de saúde e destes com a comunidade.

De acordo com o autor, a importância das ações de comunicação e de informação tem tido cada vez mais destaque nas conferências nacionais de saúde, principalmente porque estas ações viabilizariam uma maior participação no controle social das políticas de saúde. Ainda assim, para Oliveira (op. cit.), a ênfase dada a esses conceitos é muito mais instrumental e prescritiva, e não dialógica, como seria de supor ao se pensar na trajetória popular e democrática de formulação e implantação do SUS.

Não basta constatar a necessidade ou a importância da comunicação e da informação, mas o de passar desse estágio para outro em que sejam efetivados, concretamente, políticas, processos e recursos de comunicação e informação (preferencialmente dialógicos) para o exercício democrático do controle social e da participação popular no Sistema Único de Saúde (OLIVEIRA, 2004, p. 68).

Para este autor, o controle público através da participação popular nos CMS pode estar sendo dificultado pelas relações so- 


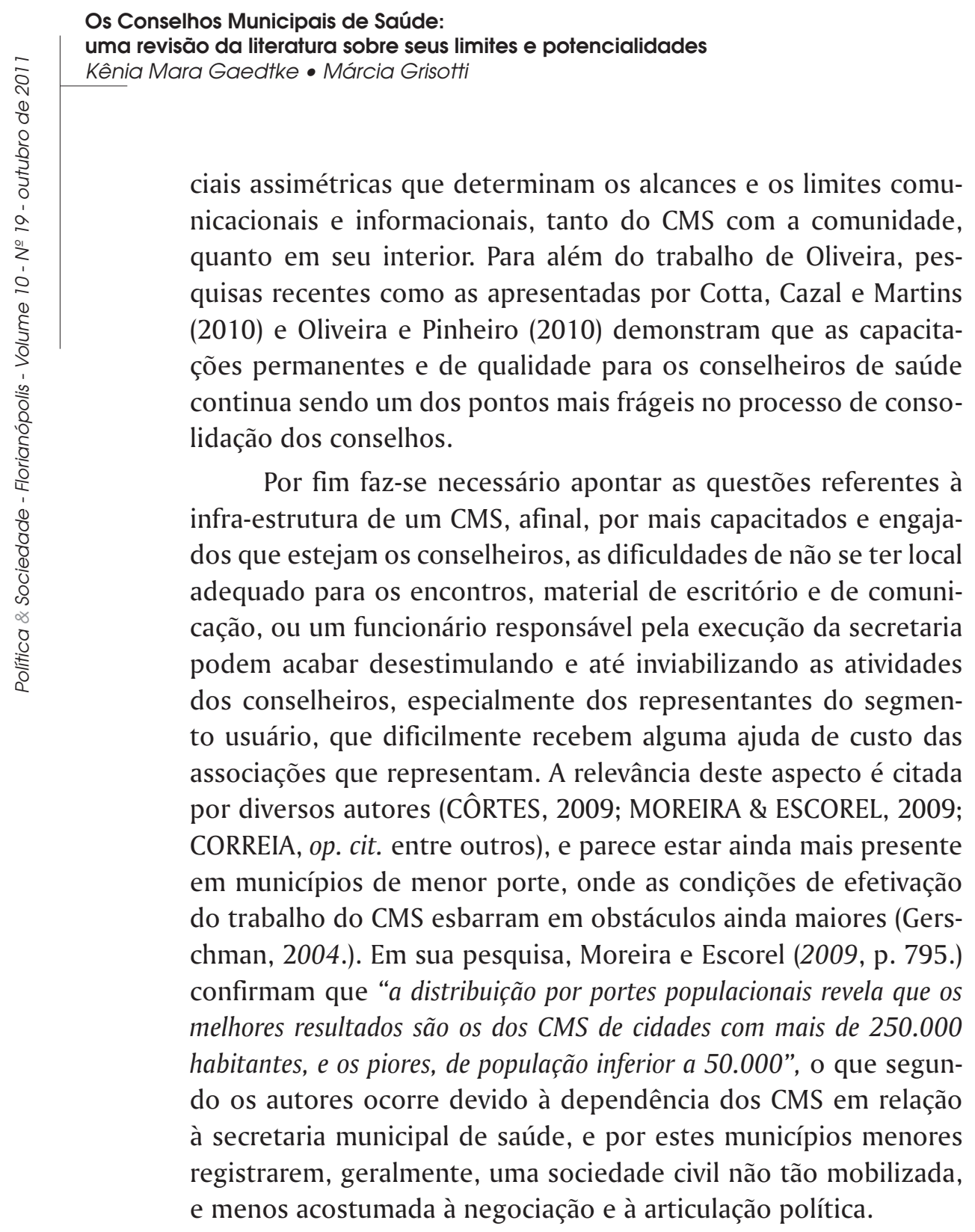

Ao menos neste ponto, é possível associar praticamente todos os autores citados: há uma confirmação de que a efetividade do CMS só se dará quando a população do município estiver ciente (e atuante) de sua existência, função e necessidade. Uma sociedade organizada e mobilizada poderá transformar um espaço meramente formal em palco de formação cidadã, negociações 
e deliberações importantes para a política de saúde do município. Segundo Gerschman (2004, p. 244), "a efetividade dos conselhos relaciona-se à pressão exercida pelos usuários, pelos movimentos sociais organizados e profissionais de saúde e à maior proximidade da população com as autoridades locais".

\section{Considerações finais}

Há hoje uma produção considerável sobre os conselhos municipais de saúde em todo o país. Longe de esgotar o debate sobre estes espaços, este número expressivo de trabalhos permite a criação de um conjunto de informações importantes não apenas para a academia, mas também (e principalmente) para as instâncias políticas, onde o constante acompanhamento dos CMS contribui para seu aprimoramento e também para a própria sociedade civil. Citando Minayo (in GRISOTTI e PATRÍCIO, op. cit., p.13): "Chegou o momento de todos os que nos empenhamos na construção do SUS termos coragem de enfrentar o lado difícil da sua implementação".

Focar a análise a partir dos limites dos CMS não desmerece o SUS, mas certamente aponta novos caminhos a serem percorridos em busca de um efetivo controle social, por parte de todos. A partir da leitura destes trabalhos, conclui-se que um dos pontos que merece maior atenção através de uma análise sociológica é, de fato, a articulação destes CMS, tanto dentro do setor saúde (através da relação com outros CMS da região, com os conselhos estadual e nacional, e com o poder executivo do município), quanto com outros setores.

Os Conselhos Municipais de Saúde, assim como os demais conselhos gestores em todo o território nacional, parecem ser marcados por avanços e retrocessos. Não há como falar em constância em um espaço que concentra tantas opiniões, expectativas e interesses diferentes. As mudanças internas - de gestão do conselho, de membros da mesa diretora ou de comissão e a entrada ou saída de algum conselheiro específico, ou funcionário da secretaria executiva - por si só já podem ser fatores que determinem o andamento dos trabalhos em um conselho. Mais do que isso, 


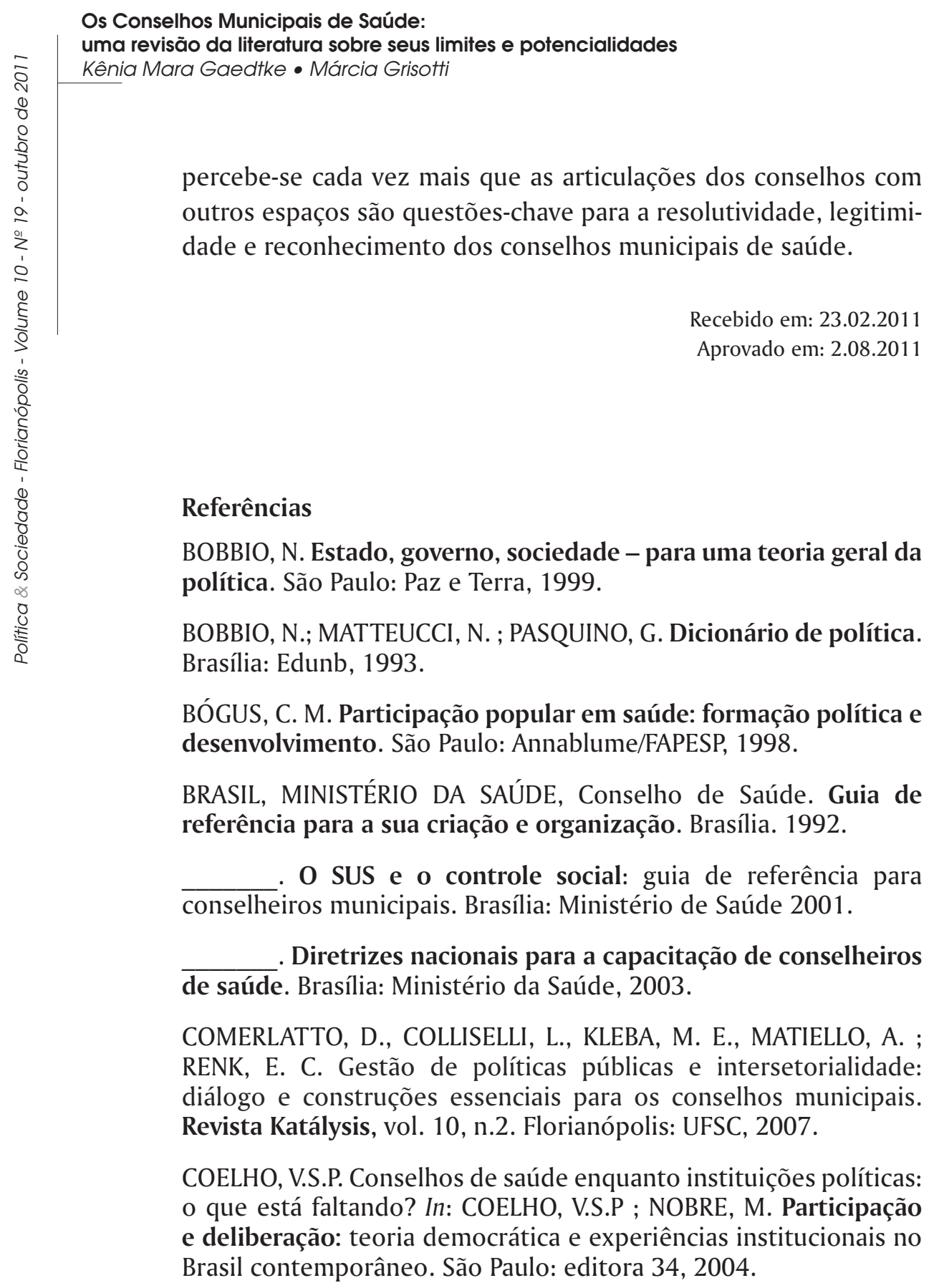


CORREIA, M.V.C.. Desafios para o controle social: subsídios para capacitação de conselheiros de saúde. Rio de Janeiro: Fiocruz, 2005.

CÔRTES, S.V. Arcabouço Institucional e participação em conselhos municipais de saúde e assistência social. In: SANTOS JUNIOR, O.A.; RIBEIRO, L.C.Q. \& AZEVEDO, S. (orgs.) Governança democrática e poder local - a experiência dos conselhos municipais no Brasil. Rio de Janeiro: Revan/Fase, 2004.

. Sistema Único de Saúde: espaços decisórios e a arena política de saúde. Cadernos de Saúde Pública [online], vol.25, número 7, 2009.

COTTA, R.M.M.; CAZAL, M.M. ; MARTINS, P.C. Conselho Municipal de Saúde: (re)pensando a lacuna entre o formato institucional e o espaço de participação social. Ciência e saúde coletiva [online]. 2010, vol.15, n.5, pp. 2437-2445.

FLEURY, S.; CARVALHO, A.I.; MANOTAS, N.; BLOCH, R.; NEVARES, S. Municipalização da saúde e poder local no Brasil. Artigo apresentado no $21^{\circ}$ ENANPAD, 1997.

GAEDTKE, K.M. As relações intersetoriais nos conselhos municipais de saúde: um estudo de caso nos conselhos de Joinville, Jaraguá do Sul e Balneário Barra do Sul - SC. Florianópolis. Dissertação (Mestrado em Sociologia Política). Universidade federal de Santa Catarina, 2011.

GERSCHMAN, S. A democracia inconclusa - um estudo da Reforma Sanitária brasileira. Rio de Janeiro: Fiocruz, 2004.

GRISOTTI, M. ; PATRICIO, Z. M. A Saúde coletiva entre discursos e práticas - A participação de usuários, trabalhadores e conselheiros de saúde. Florianópolis: UFSC, 2006.

HEINICH, C. A sociologia de Norbert Elias. Bauru: EDUSC, 2001.

HOCHMAN, G. A era do saneamento: as bases da política de saúde pública no Brasil. São Paulo: Hucitec, 2006. 
Os Conselhos Municipais de Saúde:

uma revisão da literatura sobre seus limites e potencialidades

Kênia Mara Gaedtke • Márcia Grisotti

LABRA, M.E. Conselhos de saúde: dilemas, avanços e desafios. In: LIMA, N. T. (org.) Saúde e democracia: história e perspectivas do SUS. Rio de Janeiro: Fiocruz, 2005.

LÜCHMANN, L.H.H. ; BORBA, J. Estruturas de oportunidades políticas e participação: uma análise a partir das instituições emergentes. Trabalho apresentado no XXXI Encontro Anual da ANPOCS, Caxambu/MG, 2007.

MENICUCCI, T. M. G. Público e privado na política de assistência à saúde no Brasil. Rio de Janeiro: Fiocruz, 2005.

MONNERAT, G. L. ; SOUZA, R. G. Política social e intersetorialidade: consensos teóricos e desafios práticos. Revista SER Social, Brasília, vol. 12, n. 26, p. 200-220, jan/jun 2009.

MOREIRA, M.R. ; ESCOREL, S. Conselhos Municipais de Saúde: um debate sobre a democratização da política de saúde nos vinte anos do SUS. Revista Ciência e Saúde Coletiva (especial Dossiê 20 anos SUS). Rio de Janeiro: Abrasco, 2009.

MORITA I.; GUIMARÃES, J.F.C. ; MUZIO, B.P.A Participação de Conselheiros Municipais de Saúde: solução que se transformou em problema? Revista Saúde e Sociedade. Vol. 15, n. 1, 2006.

OLIVEIRA, L.C. ; PINHEIRO, R. A participação nos conselhos de saúde e sua interface com a cultura política. Revista Ciência e Saúde Coletiva [online]. Vol, 15, n. 5, 2010.

OLIVEIRA, V. C. Comunicação, informação e participação popular nos Conselhos de Saúde. Revista Saúde e Sociedade [online] v.13, n.2, 2004.

SANTOS JUNIOR, O.A.; RIBEIRO, L.C.Q. ; AZEVEDO, S. (orgs.) Governança democrática e poder local - a experiência dos conselhos municipais no Brasil. Rio de Janeiro: Revan/Fase, 2004.

TEIXEIRA, S.F. ; OLIVEIRA, J.A.A. (Im)previdência social: 60 anos de história da Previdência no Brasil. Petrópolis: Vozes/Abrasco, 1986.

WENDHAUSEN, A. Micropoderes no cotidiano de um conselho de saúde. In: KLEBA, M.E. ; HASS, M. (orgs.) Dossiê gestões públicas democráticas e experimentos participativos. Chapecó: Argos, 2005. 


\section{Abstract \\ The Municipal Health Councils: a literature review of their limits and potentialities}

The unprecedented nature and extension of the health councils as an action of the State has brought a considerable increase in academic researches on this topic. They agree that the institutionalization of health councils does not necessarily guarantee effective social control, participation and democratization in health care policies. This paper seeks to review part of this literature, mapping the limits indicated and presenting them through the relationships established inside and outside of the municipal health councils. We expect to show that the difficulties met by councils for their effectiveness and legitimacy are related to several interdependent factors, which, if analyzed per se can lead to simplistic conclusions.

Keywords: Unified Health System, Health Councils, participation, social control. 